\title{
Microelectrode Arrays Modified with Nanocomposites for Monitoring Dopamine and Spike Firings Under Deep Brain Stimulation in Rat Models of Parkinson's Disease
}

\author{
Guihua Xiao ${ }^{1,2}$, Yilin Song1,2, Yu Zhang ${ }^{1,2}$, Yu Xing1,2, Hongyan Zhao ${ }^{3}$, Jingyu Xie ${ }^{1,2}$, Shengwei \\ $\mathrm{Xu}^{1,2}$, Fei Gao ${ }^{1,2}$, Mixia Wang ${ }^{1,2}$, Guogang Xing ${ }^{3}$, Xinxia Cai ${ }^{1,2^{*}}$ \\ ${ }^{1}$ State Key Laboratory of Transducer Technology, Institute of Electronics, Chinese Academy of Sciences, \\ Beijing 100190, PR China \\ ${ }^{2}$ University of Chinese Academy of Sciences, Beijing 100049, PR China \\ ${ }^{3}$ Key Laboratory for Neuroscience, Ministry of Education and Ministry of Public Health Neuroscience \\ Research, Institute and Department of Neurobiology, Peking University, Beijing 100191, PR China \\ *Corresponding Email: xxcai@mail.ie.ac.cn
}

KEYWORDS: MEA, Dopamine, Spikes, DBS, Parkinson's Disease Rats, In Vivo, Nanocomposites

DA level is measured in many researches during DBS in different brain region. The different detection methods, stimulation parameters on the different areas of brain is shown on table 1. The table is also added as the supplementary method at the discussion part.

Note that the levels of evoked dopamine were specific to the individual animal as the average concentration of dopamine was significantly different among the rats. The simulation frequency, time of duration, pulse width and current intensity would affect the DA release in the brain, and different DA concentration would be detected in the different brain region stimulating in different target. As can be seen, the released DA concentration after DBS was recorded at different level using amperometry and FSCV methods. Y.M Shon ${ }^{[1]}$ showed that the extracellular DA concentration after stimulus exhibited a relatively high degree of variance between animals from $1 \sim 4 \mu \mathrm{M}$. The heterogeneity of dopaminergic innervation where the recording electrode located ${ }^{[2]}$ and the precise location of the stimulating electrode affected the attained DA concentration.

The DA level (PD rat) after DBS in this work is a little higher than the other work (normal animal) using FSCV method.

First, we think the different methods have different selectivity to the interferences. As discussed in the supplementary material, the selectivity to the common interferences achieved $90 \%$ in the amperometry and FSCV method. The brain fluid is highly complex and some unknow molecule may contribute to the oxidation current. Additionally, DA level is also various by a few micromoles in amperometry and FSCV method. As shown in Wightman's work ${ }^{[3]}$, the DA concentration obtained with amperometry was greater $(\sim 3 \mu \mathrm{M})$ than with cyclic voltammetry.

Second, the different brain region will release different DA concentration. In the M.K.Zachek's work ${ }^{[4]}$, different level from $0.8 \mu \mathrm{M}$ to $2.8 \mu \mathrm{M}$ was obtained on four recording channels in Nucleus accumbens. The results demonstrate DA concentration would be different at different recording positions.

Third, the stimulation parameters have a close relationship on DA release. As shown in Z.Yang's work ${ }^{[5]}$, it shows that DA concentration have a different relationship with each parameters. The combined stimulation parameters would

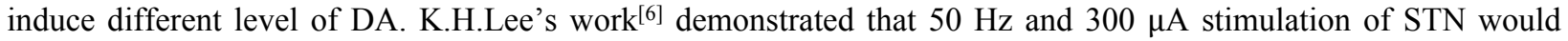
produce the optimal response, and the evoked DA response falling off at greater frequency or intensity. In the next step, we will test those factors related with DA release level in vivo experiment. We will confirm our result by using different detection method, stimulation parameters and interested brain region. 
Table S1. Changes of DA concentration after DBS in different publications.

\begin{tabular}{|c|c|c|c|c|c|c|}
\hline Author & Animal & $\begin{array}{l}\text { Stimulation } \\
\text { Parameters }\end{array}$ & $\begin{array}{l}\text { Brain } \\
\text { regio } \\
\mathrm{n} \\
\text { stimu } \\
\text { lated }\end{array}$ & $\begin{array}{l}\text { Brain } \\
\text { region } \\
\text { release }\end{array}$ & $\begin{array}{l}\text { Detection } \\
\text { method }\end{array}$ & $\begin{array}{l}\text { DA } \\
\text { concentration }\end{array}$ \\
\hline C.Dugast ${ }^{[7]}$ & $\begin{array}{l}\text { Normal } \\
\text { Rat }\end{array}$ & $\begin{array}{l}\text { Frequency: } 20 \mathrm{~Hz} \text {; } \\
\text { Pulses: 6; } \\
\text { Pulse width:0.5 ms; } \\
\text { Intensity: } 300 \mu \mathrm{A} \text {; }\end{array}$ & MFB & $\begin{array}{l}\text { Nucleus } \\
\text { accumben } \\
\text { s }\end{array}$ & $\begin{array}{l}\text { CFM; } \\
\text { Amperometry }\end{array}$ & $1.31 \mu \mathrm{M}$ \\
\hline Y.M.Shon ${ }^{[1]}$ & $\begin{array}{l}\text { Normal } \\
\text { Pig }\end{array}$ & $\begin{array}{l}\text { Frequency: } 120 \mathrm{~Hz} \text {; } \\
\text { Pulses: ---; } \\
\text { Pulse width: } 0.5 \mathrm{~ms} \text {; } \\
\text { Intensity: } 7 \mathrm{~V} \text {; }\end{array}$ & STN & striatum & $\begin{array}{l}\text { CFM; } \\
\text { FSCV }\end{array}$ & $4 \mu \mathrm{M}$ \\
\hline Z.Yang $^{[5]}$ & $\begin{array}{l}\text { Normal } \\
\text { Rat }\end{array}$ & $\begin{array}{l}\text { Frequency: } 80 \mathrm{~Hz} \text {; } \\
\text { Pulses: } 200 \text {; } \\
\text { Pulse width: ---; } \\
\text { Intensity: } 1000 \mu \mathrm{A} \text {; }\end{array}$ & MFB & $\mathrm{CPu}$ & $\begin{array}{l}\text { CFM; } \\
\text { FSCV }\end{array}$ & $5.48 \mu \mathrm{M}$ \\
\hline M.K.Zachek ${ }^{[4]}$ & $\begin{array}{l}\text { Normal } \\
\text { Rat }\end{array}$ & $\begin{array}{l}\text { Frequency: } 60 \mathrm{~Hz} \text {; } \\
\text { Pulses:40; } \\
\text { Pulse width: } 2 \mathrm{~ms} \text {; } \\
\text { Intensity: } 300 \mu \mathrm{A}\end{array}$ & MFB & $\begin{array}{l}\text { Nucleus } \\
\text { accumben } \\
\text { s }\end{array}$ & $\begin{array}{l}\text { Tungsten- } \\
\text { MEA } \\
\text { FSCV }\end{array}$ & $\begin{array}{l}0.8 \mu \mathrm{M} ; \\
1.8 \mu \mathrm{M} ; \\
2.8 \mu \mathrm{M}\end{array}$ \\
\hline H.M.Schwerdt ${ }^{[8]}$ & $\begin{array}{l}\text { Normal } \\
\text { Rat }\end{array}$ & $\begin{array}{l}\text { Frequency: } 60 \mathrm{~Hz} \\
\text { Pulses: } 24,48,72 ; \\
\text { Pulse width: } 2 \mathrm{~ms} \\
\text { Intensity: } \\
\text { 200,250,300 } \mu \mathrm{A} ;\end{array}$ & MFB & $\begin{array}{l}\text { Ipsilateral } \\
\text { striatum }\end{array}$ & $\begin{array}{l}\text { uIPs; } \\
\text { FSCV }\end{array}$ & $0.7 \mu \mathrm{M}$ \\
\hline This work & PD Rat & $\begin{array}{l}\text { Frequency: } 100 \mathrm{~Hz} \text {; } \\
\text { Duration:10 s; } \\
\text { Pulse width: } 60 \mu \mathrm{s} ; \\
\text { Intensity: } 300 \mu \mathrm{A} \text {; }\end{array}$ & GPi & $\begin{array}{l}\text { Bilateral } \\
\mathrm{CPu}\end{array}$ & $\begin{array}{l}\text { MEA; } \\
\text { Amperometry }\end{array}$ & $\begin{array}{l}\text { Ipsilateral: } \\
7.33 \mu \mathrm{M} \text {; } \\
\text { Contralateral: } \\
3.33 \mu \mathrm{M}\end{array}$ \\
\hline
\end{tabular}

MFB: medial forebrain bundle; STN: subthalamus nuchus; GPi: globus pallidus internas; uIPs: micro-invasive Probes; MEA: Microelectrode arrays; CPu: Caudate Putamen;

CFM: carbon-fiber microelectrode; FSCV: fast scan cyclic voltammetry

The amperometry and fast scan cyclic voltammetry method were used to test our microelectrode arrays (MEA) and compared in the sensitivity, linearity and selectivity. Autolab PGSTAT302N electrochemical workstation (Autolab, Switzerland) was used in the following experiments that is different with BioLogic VMP3 multichannel Potentiostat used in the in vivo testing.

The MEA at the temporal resolution of $0.01 \mathrm{~s}$ was tested. As shown in Figure S1, the calibration curve (Figure.S1a) and current plotted with concentration curve (Figure.S1b) demonstrate the possibility to detect dynamic dopamine (DA) level. The typical calibration curve in Figure S1a shows a stable current response when different DA solution was added. The temporal resolution in amperometry method still need to be improved. We are also working on improving the temporal resolution of our homemade electrochemical instruments. 

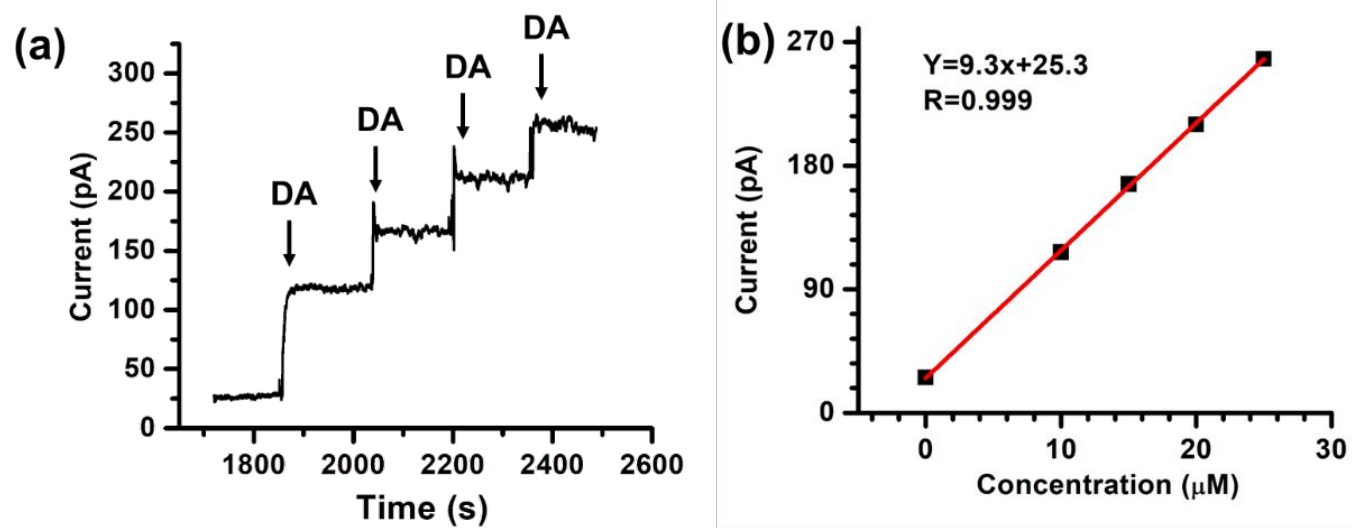

Figure S1. The MEA respond to DA solution with the temporal resolution at 0.01 s. (a) A typical calibration curve by adding $10 \mu M, 5 \mu M, 5 \mu M, 5 \mu M D A$ solution. (b) DA current response is plotted with the corresponding concentration.

In our brain, the $\mathrm{pH}$ range in extracellular fluid is 6 to 8. Therefore, selectivity in acidic $(\mathrm{pH}=6)$, neutral $(\mathrm{pH}=7)$ and alkaline $(\mathrm{pH}=8)$ solution were tested. The common interferences in the brain like serotonin (5-HT), ascorbic acid (AA), uric acid (UA), 3,4-dihydroxyphenylacetic (Dopac) and glutamate (Glu) would affect the DA current response. 5-HT belongs to the monoamine family that has a similar molecule structure as DA. AA has a very high concentration in the brain. UA, Glu, Dopac are the common chemicals in our brain.

As shown in Figure $\mathrm{S} 2$, four electrodes were tested in the different solution with different $\mathrm{pH}$ value $(\mathrm{pH}=6,7,8)$. Figure S2a shows the current response of DA and different interferences. Current response of DA (10 $\mu \mathrm{M}), \mathrm{DA}$ $(10 \mu \mathrm{M})$ and 5-HT $(10 \mu \mathrm{M})$, DA $(10 \mu \mathrm{M})$ and AA $(10 \mu \mathrm{M})$, DA $(10 \mu \mathrm{M})$ and $\mathrm{UA}(10 \mu \mathrm{M})$, DA $(10 \mu \mathrm{M})$ and Dopac $(10 \mu \mathrm{M})$, DA $(10 \mu \mathrm{M})$ and Glu $(10 \mu \mathrm{M})$ were recorded. Note that the interferences induce the current shifting compared with pure DA solution. The selectivity result is shown in Figure S2b.

The selectivity is calculated by the equation:

\section{Selectivity=1-I(interference)/I(DA)}

The I(interference) is the current response of the interested interference. The I(DA) is the current response of DA. The selectivity result demonstrates that $\mathrm{pH}$ value would affect the selectivity at some certain degree. Note that the mean selectivity to 5-HT, AA, UA, Dopac, Glu is above $90 \%$. 

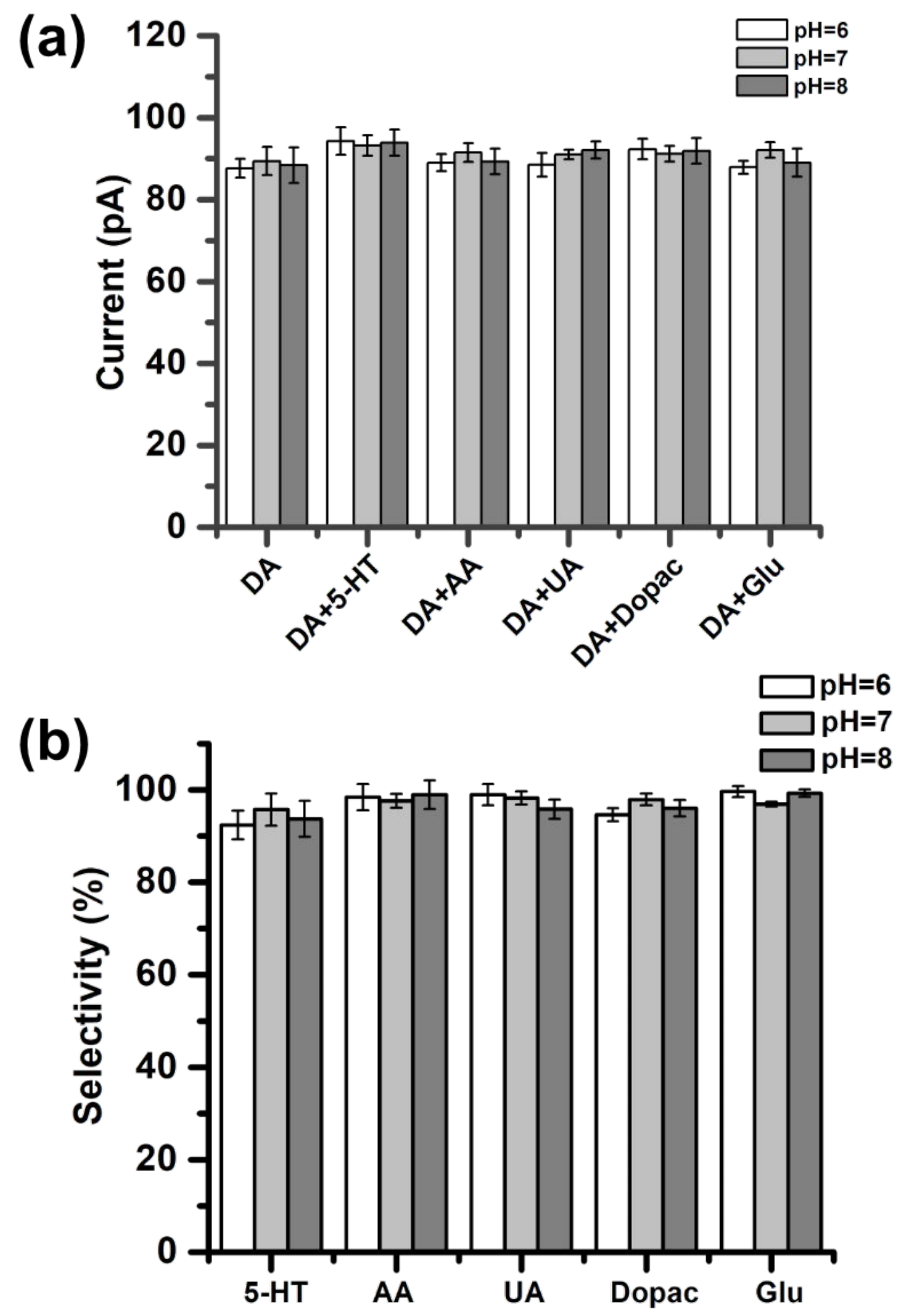

Figure S2. MEA selectivity to 5-HT, AA, UA, Dopac, Glu in the solution of different pH (6,7,8). (a) Current response of DA and interferences solution. (b) Selectivity to the common interferences. 
Fast scan cyclic voltammetry was used to confirm the results of amperometry method. A typical triangle waveform is applied to the electrode as shown in Figure S3. The scan rate is $300 \mathrm{~V} / \mathrm{s}$. The scan potential from $0.4 \mathrm{~V}$ to $+1.0 \mathrm{~V}$ and back to $-0.4 \mathrm{~V}$ is applied. The scan rate and potential range determine the length of each waveform which is $9.3 \mathrm{~ms}$. The waveform is repeated every $100 \mathrm{~ms}$. Each waveform is shown in Figure S4a.

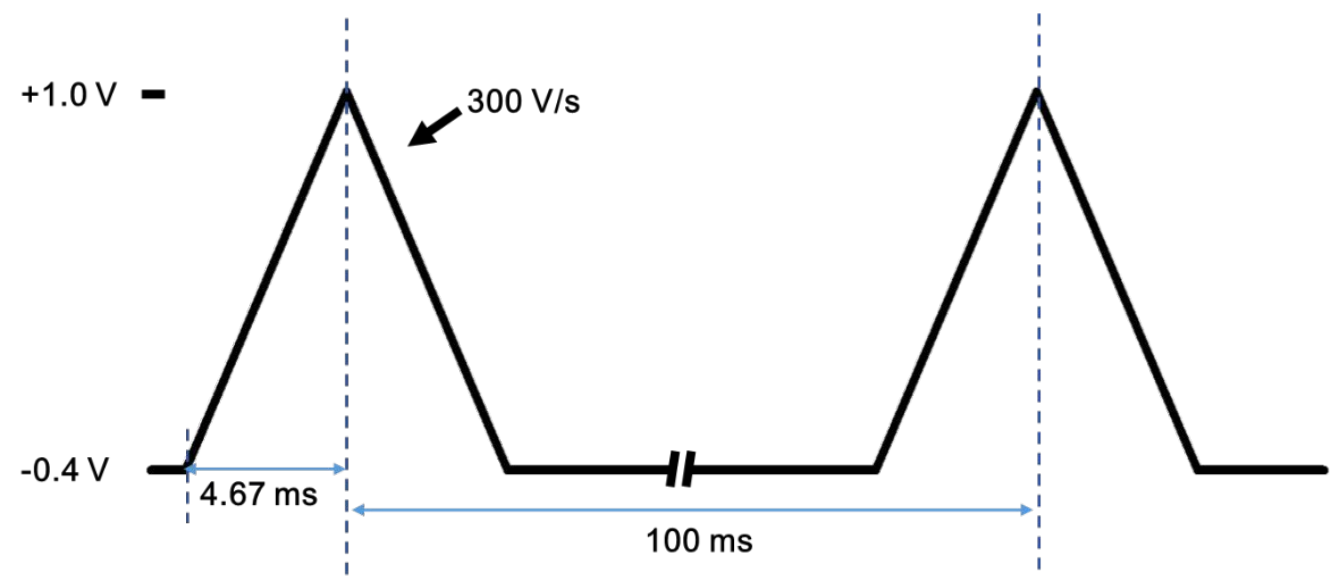

Figure S3. The triangle waveform that applied to the electrode.

The applied waveform, corresponding MEA response and background-subtracted cyclic voltammetry are shown in Figure S4. The potential applied to the MEA is ramped from $-0.4 \mathrm{~V}$ to $+1.0 \mathrm{~V}$ and back at a scan rate of $300 \mathrm{~V} / \mathrm{s}$ (Figure S4a). During fast scan cyclic voltammetry, a large background current is produced. As shown in Figure S4b, the background current is huge that is plotted vs applied potential (black curve). The red curve is the corresponding current observed in the presence of $10 \mu \mathrm{M}$ DA. By subtracting out the background, a cyclic voltammogram for DA is generated (Figure S4c). Changes in the DA current are visualized by subtracting the background current at the peak oxidation potential. The peak oxidation potential of $\mathrm{DA}$ is $0.138 \mathrm{~V} \mathrm{vs} \mathrm{Ag} / \mathrm{AgCl}$ reference. 

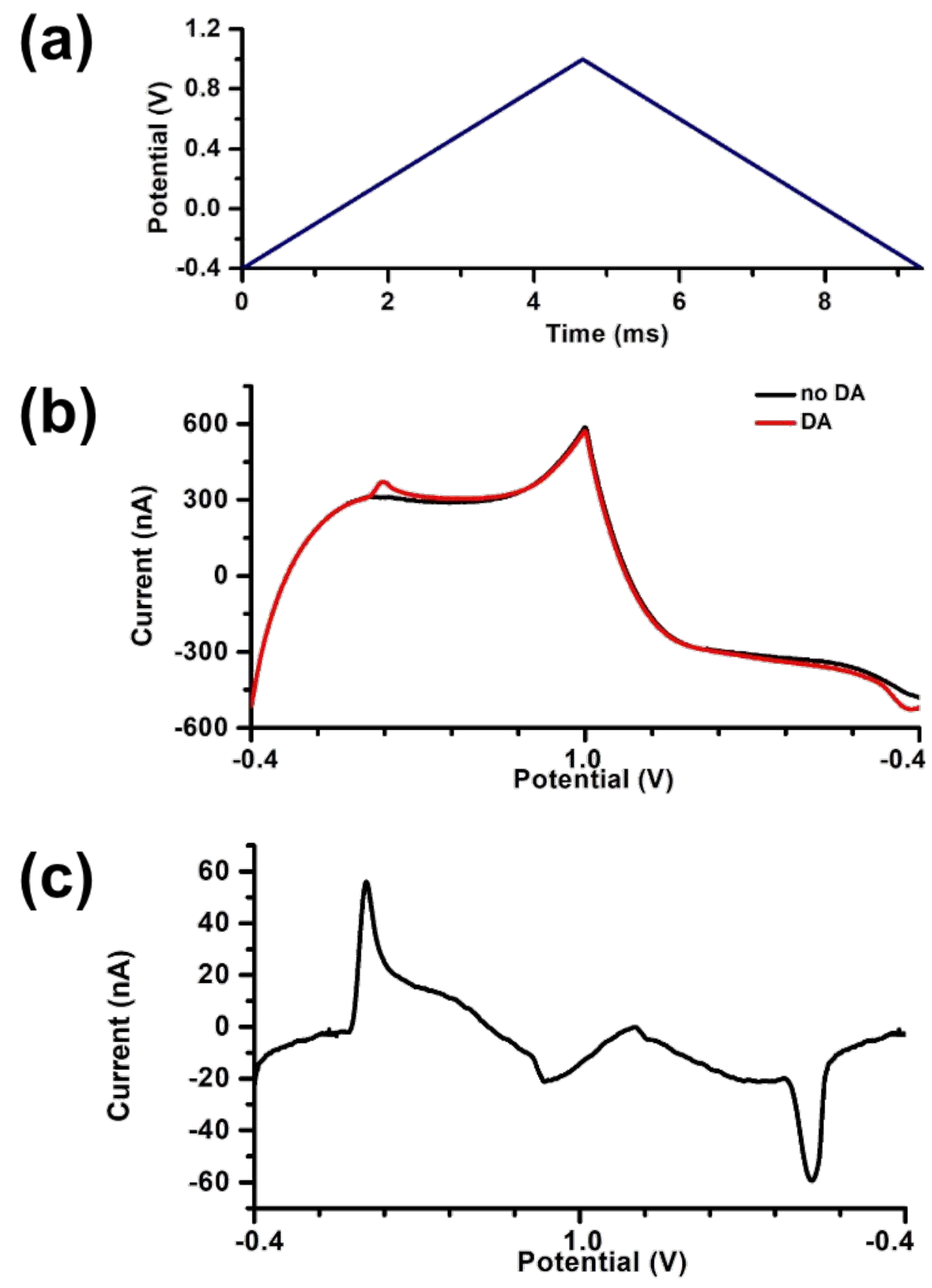

Figure S4. MEA response by applying fast-scan cyclic voltammetry. (a) A single waveform applied in the electrode. (b)Current plotted with potential in the solution with (red) and without (black) DA. (c) Backgroundsubtracted cyclic voltammetry of $D A$.

DA solution with different concentration is added to test the sensitivity of MEA electrodes. Bare solution, 10 $\mu \mathrm{M}, 15 \mu \mathrm{M}, 20 \mu \mathrm{M}, 25 \mu \mathrm{M}$ DA solution were tested. 50 cycles are applied in each solution for $5 \mathrm{~s}$. As shown in Figure S5a, the current vs potential curve of one cycle is extracted to demonstrate the different response of MEA at peak oxidation potential $(0.138 \mathrm{~V})$. A tiny current change emerges at $0.138 \mathrm{~V}$. The backgroundsubtracted cyclic voltammetry is shown in Figure S5b with a significant peak oxidation current. The peak 
current increased as the concentration increased. As shown in Figure S5c, the current value at peak oxidation potential is plotted vs time to illustrate the dynamic variation of DA. Note that the electrode is very sensitive to the DA solution. The sensitivity is $4.42 \mathrm{nA} / \mu \mathrm{M}$. The linearity is 0.998 (Figure S5d).
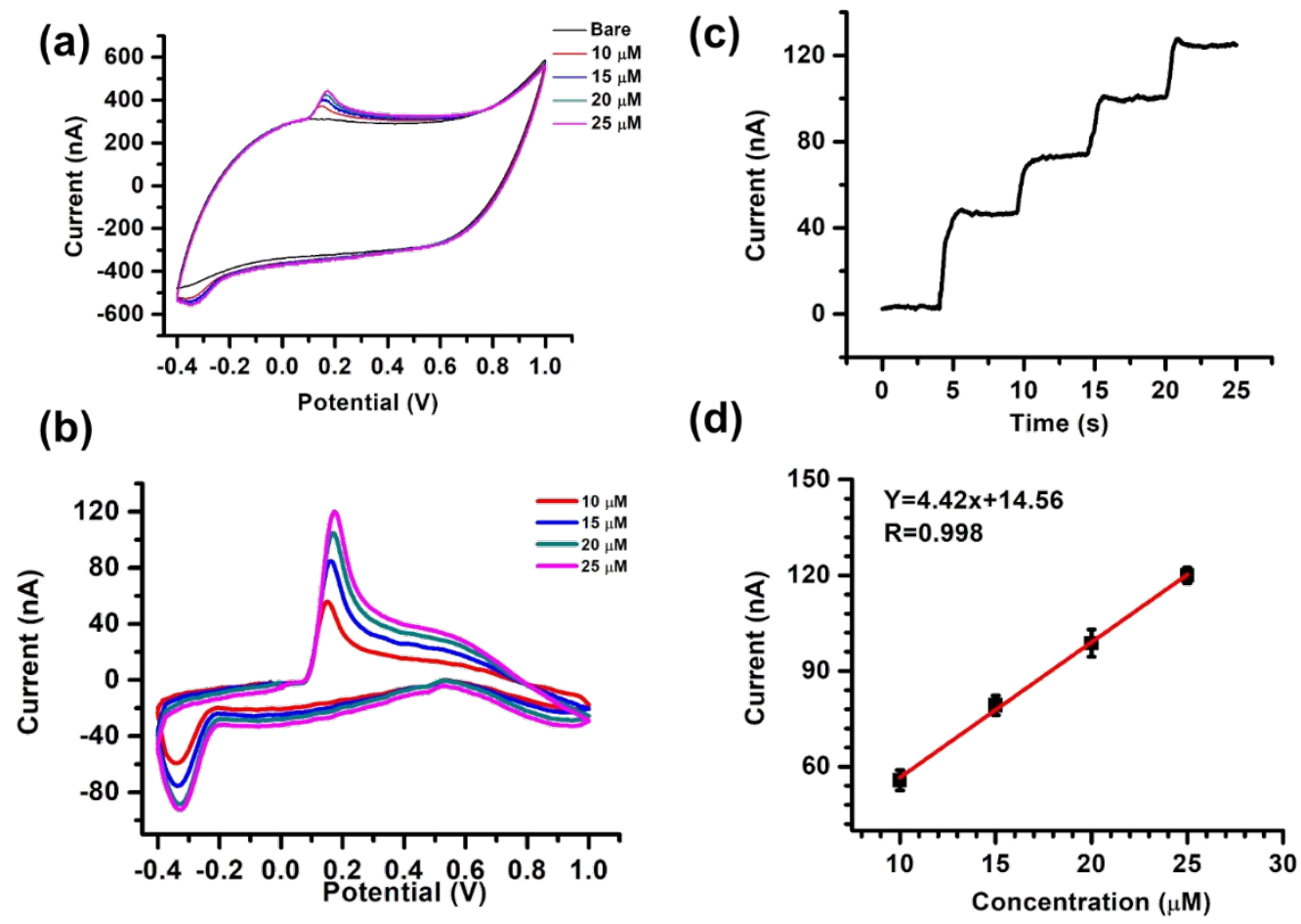

Figure S5. MEA respond to different DA concentration by fast scan cyclic voltammetry method. (a) Cyclic voltammetry of current vs potential curve at different DA solution. (b) Background-subtracted cyclic voltammetry of DA. (c) The current at the peak oxidation potential vs time curve. (d) The DA current response is plotted with the concentration.

The common interferences were tested by fast scan cyclic voltammetry method. Cyclic voltammogram of 10 $\mu \mathrm{M} D A$ and common interference is shown in Figure S6. DA has a peak oxidation current at $0.138 \mathrm{~V}$. The vertical dashed line denotes the oxidation peak for DA (Figure S6). For 5-HT, the cyclic voltammogram shows a peak potential near 0.4 V. UA and AA have a broad oxidation wave attributable to slow electron-transfer kinetics. The Glu shows a peak oxidation near 0.6 V that is far from DA's peak oxidation. Dopac shows current response begin from $0.4 \mathrm{~V}$. Those results show a satisfied selectivity of MEA to the interferences. 
(a)

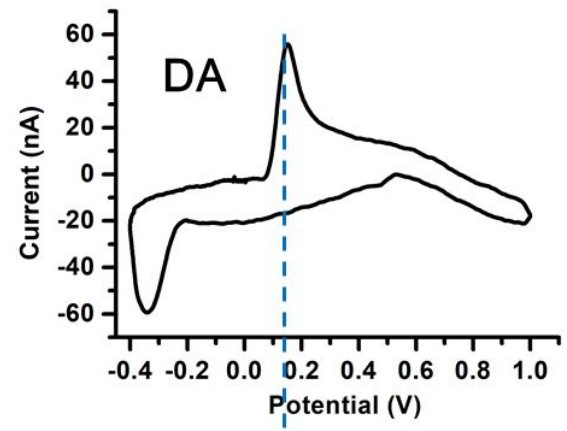

(b)

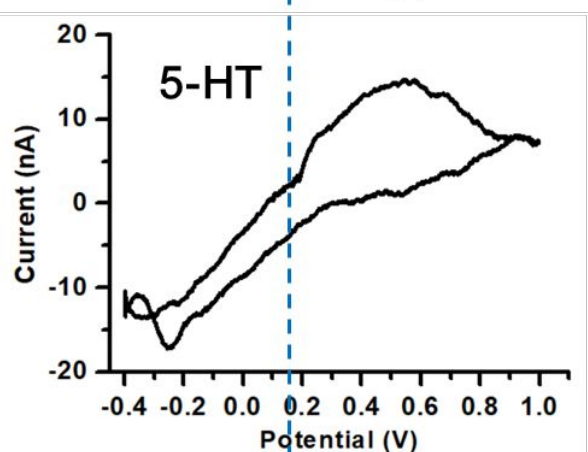

(c)

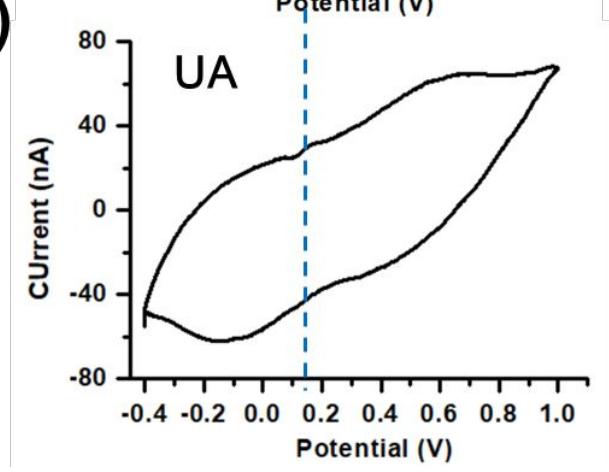

(d)

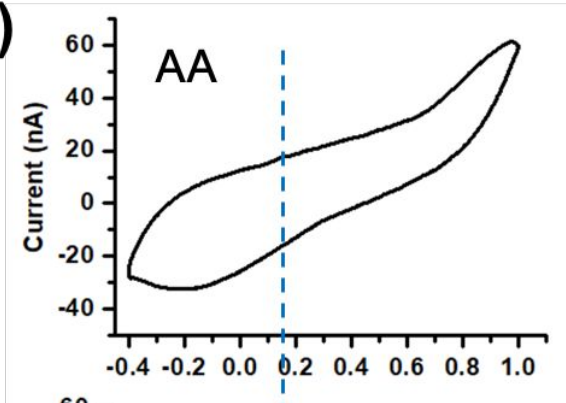

(e)

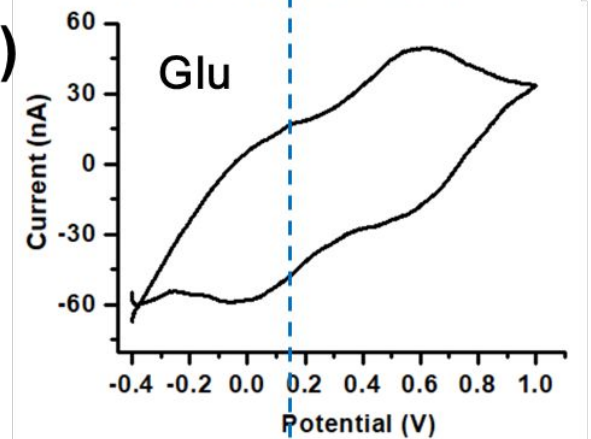

(f)

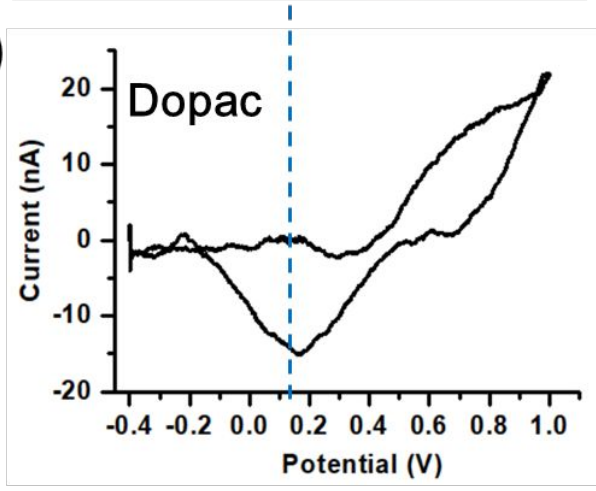

Figure S6. Cyclic voltammograms of different neurotransmitters including DA (a), 5-HT (b), UA (c), AA (d), Glu (e), Dopac (f).

We compared the sensitivity of fast scan cyclic voltammetry and amperometry. The MEA shows a very high sensitivity during DA detection with fast scan cyclic voltammetry method. As shown in Figure S7, current response in the fast scan cyclic voltammetry method presents a good linearity to the current response in amperometry method, with a correlation coefficient of 0.990 . That means those two methods show a similar response trends during DA detection. 


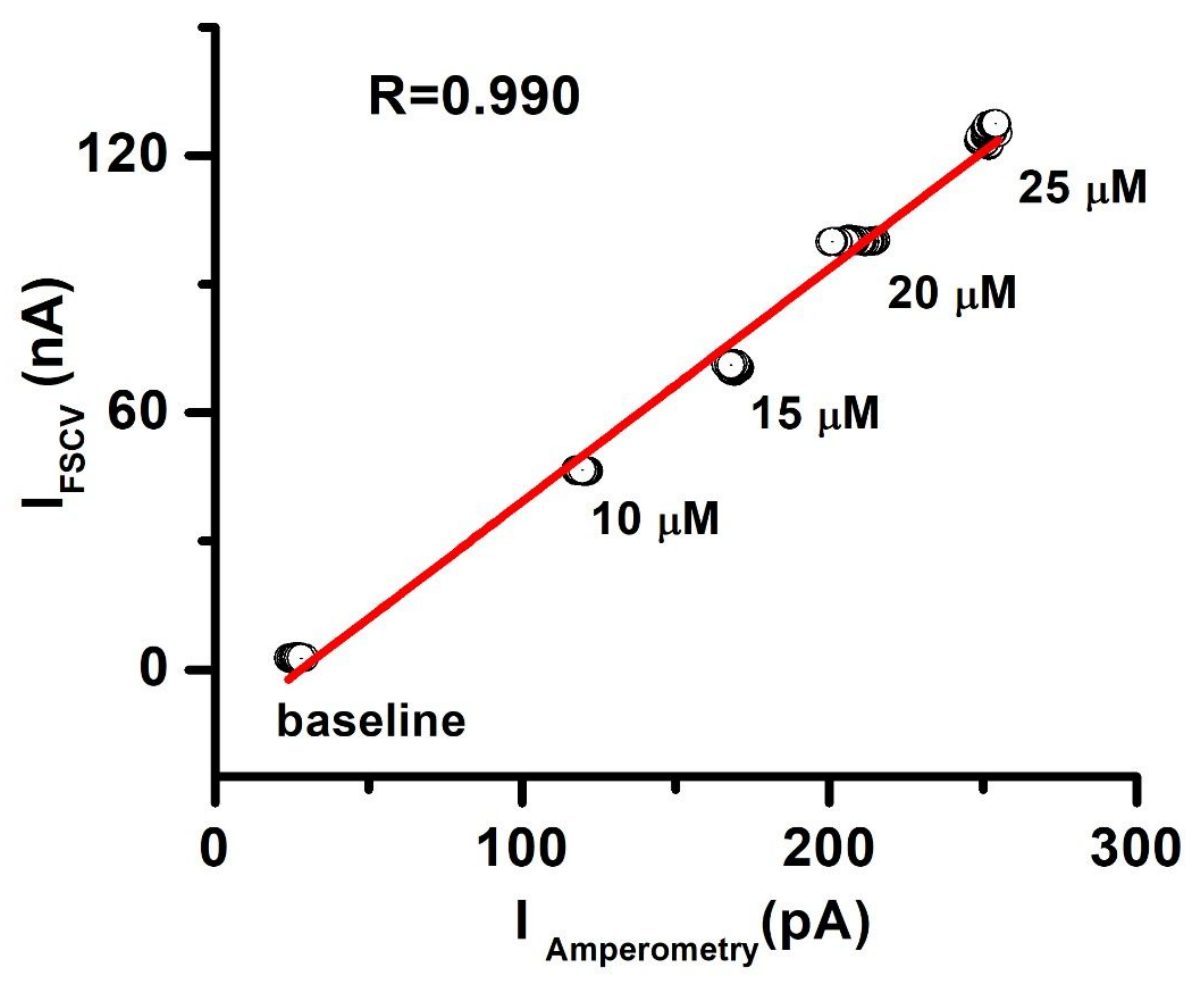

Figure S7. The correlation of current response between amperometry method and fast scan cyclic voltammetry method.

By comparing the amperometry method and fast scan cyclic voltammograms method applying to our MEA, the cyclic voltammograms method shows a relative higher sensitivity to DA solution and good selectivity to the interferences. This method with high temporal resolution shows good advantages in the low concentration detection. In the future, we will apply this new method into the in vivo DA recording. Fast scan cyclic voltammograms would provide a new insight for us to monitor the low concentration of chemicals. We are improving the MEA and our homemade electrochemical measurement instrument to meet more requirements of in vivo monitoring.

\section{Reference:}

(1) Shon, Y. M.; Lee, K. H.; Goerss, S. J.; Kim, I. Y.; Kimble, C.; Van Gompel, J. J.; Bennet, K.; Blaha, C. D.; Chang, S.Y. High frequency stimulation of the subthalamic nucleus evokes striatal dopamine release in a large animal model of human DBS neurosurgery. Neuroscience Letters, 2010, 475(3), 136-140.

(2) Nomoto, M.; Kaseda, S.; Iwata, S.; Shimizu, T.; Fukuda, T.; Nakagawa, S. The metabolic rate and vulnerability of dopaminergic neurons, and adenosine dynamics in the cerebral cortex, nucleus accumbens, caudate nucleus, and putamen of the common marmoset. Journal of Neurology, 2000, 247 Suppl 5(5), V16-V22.

(3) Kawagoe, K. T.; Wightman, R. M. Characterization of amperometry for in vivo measurement of dopamine dynamics in the rat brain. Talanta, 1994, 41(6), 865-874.

(4) Zachek, M. K.; Takmakov, P.; Park, J.; Wightman, R. M.; McCarty, G.S. Simultaneous monitoring of dopamine concentration at spatially different brain locations in vivo. Biosensors \& Bioelectronics, 2010, 25(5), 1179-1185.

(5) Yang, Z.; Yang, X.; Xie, J.; Christopher, D. E.; Wolfgang, H. O. Monitoring dopamine release of rats using fast cyclic voltammetry in vivo. Chinese Journal of Neuroanatomy, 1999, 3, 301-303. 
(6) Lee, K. H.; Blaha, C. D.; Harris, B. T.; Cooper, S.; Hitti , F. L.; Leiter, J. C.; Roberts, D.W.; Kim, U. Dopamine efflux in the rat striatum evoked by electrical stimulation of the subthalamic nucleus: potential mechanism of action in Parkinson's disease. European Journal of Neuroscience, 2010, 23(4), 10051014.

(7) Dugast, C.; Suaud-Chagny, M. F.; Gonon, F. Continuousin vivo monitoring of evoked dopamine release in the rat nucleus accumbens by amperometry. Neuroscience, 1994, 62(3), 647-654.

(8) Schwerdt, H.; Zhang, E.; Kim, M.; Yoshida,T.; Stanwicks, L.; Amemori, S.; Dagdeviren,H.; Langer, R.; Cima, M.; Graybiel, A. Cellular-scale probes enable stable chronic subsecond monitoring of dopamine neurochemicals in a rodent model. Communications Biology. 2018, 1(144), 1-10. 